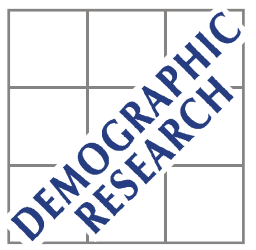

Demographic Research a free, expedited, online journal of peer-reviewed research and commentary in the population sciences published by the Max Planck Institute for Demographic Research Konrad-Zuse Str. 1, D-18057 Rostock · GERMANY www.demographic-research.org

DEMOGRAPHIC RESEARCH

VOLUME 23, ARTICLE 36, PAGES 1031-1048

PUBLISHED 30 NOVEMBER 2010

http://www.demographic-research.org/Volumes/Vol23/36/

DOI: $10.4054 /$ DemRes.2010.23.36

Descriptive Findings

\title{
Variations in attitudinal gender preferences for children across 50 less-developed countries
}

Kana Fuse

(C)2010 Kana Fuse.

This open-access work is published under the terms of the Creative Commons Attribution NonCommercial License 2.0 Germany, which permits use, reproduction \& distribution in any medium for non-commercial purposes, provided the original author(s) and source are given credit.

See http:// creativecommons.org/licenses/by-nc/2.0/de/ 


\section{Table of Contents}

1 Introduction 1032

2 Data and methods $\quad 1035$

3 Results 1036

4 Conclusions 1042

5 Limitations 1043

$\begin{array}{lll}6 & \text { Policy implications } & 1044\end{array}$

$\begin{array}{lll}7 & \text { Acknowledgments } & 1044\end{array}$

References 1046 


\title{
Variations in attitudinal gender preferences for children across 50 less-developed countries
}

\author{
Kana Fuse ${ }^{1}$
}

\begin{abstract}
While a number of studies have examined gender preferences for children by studying behavioral measures, such as skewed sex ratios, sex imbalance in infant mortality, and sibling size/order; attitudinal measures have been analyzed less systematically. Using 50 Demographic and Health Surveys conducted between 2000 and 2008, this paper seeks to advance our understanding of gender preferences in developing countries by examining attitudinal measures cross-nationally. This study's findings show that, while balance preference is the most common type of preference in the vast majority of countries, countries/regions vary in the prevalence of son and daughter preferences. A preference for sons is not always found; and, indeed, a preference for daughters is shown to prevail in many societies.
\end{abstract}

${ }^{1}$ JICA Research Institute, Japan International Cooperation Agency (JICA). 10-5 Ichigaya Honmura-cho, Shinjuku-ku, Tokyo 162-8433, Japan. E-mail: Fuse.Kana@jica.go.jp 


\section{Introduction}

Gender preferences for children have been widely observed around the globe. Considerable attention has been devoted to this issue because parental gender preferences can cause discriminatory practices against children of the less-desired sex, and these practices can have unfavorable social and demographic consequences. For example, pronounced gender preferences can lead to sex-selective abortions, and hence to skewed sex ratios at birth (see, for example, Goodkind 1996). In China and India, where son preference prevails, it has been predicted that an imbalance in the sex ratio of the population arising from a skewed sex ratio at birth will produce a sex imbalance in the marriage market due to a shortage of marriageable women (see, for example, Guilmoto 2010). Gender preferences for children can also result in sex differentials in infant and child mortality. Since female children are biologically less vulnerable than males (Waldron 1983), female children typically have lower mortality rates than male children. Nonetheless, female infant/child mortality rates exceed male infant/child mortality in some societies, which suggests that adults who favor boys over girls may be engaging in discriminatory practices (United Nations 2000; Waldron 1998). A related negative consequence arises from parental gender bias in the provision of basic care, such as breastfeeding, nutrition, immunizations, medical treatment, and schooling. Therefore, this gender bias may affect the health and well-being of children.

Many previous studies have examined gender preferences for children, especially son preference in South Asia, East Asia, and the Middle East. Most of them have studied the extent of gender preference through observable behavior measures, such as the practice of sex-selective abortions, imbalances in sex ratios, sex differentials in infant/child mortality, and gender disparities in the health and well-being of children. A number of studies have also looked at gender preference in terms of parity progression, and the contraceptive use of women with certain sex compositions of surviving children. Using these different methods, scholars have found evidence for gender preferences for children around the globe.

While gender preferences for children have been examined rigorously in terms of behavioral measures, attitudinal measures have been less systematically analyzed. In this paper, I suggest that attitudinal measures of gender preference are well-suited for a cross-national comparison across a wide range of less-developed countries. By presenting recent distributions of gender preference attitudes from 50 less-developed countries, this paper shows how gender preferences vary widely within and across countries.

Gender preferences for children are associated with various types of reproductive behavior, depending on the societal context. Specifically, whether and how women's gender preferences translate into behavior may differ based on various societal-specific 
aspects, such as the level of fertility, the degree of access to modern birth control methods, and the cultural acceptability of prenatal and postnatal strategies of gender discrimination.

In societies in which couples have the resources and the means to achieve their reproductive goals (i.e., access to modern birth control methods and to sex-screening technology), gender preferences are likely to translate into behaviors such as the abortion of fetuses of the undesired sex, or the cessation of childbearing after the desired sex composition of children has been achieved. These types of behaviors are especially likely to occur in countries with relatively low or declining fertility, where birth control is widely available. For example, Chung and Das Gupta (2007) found that son preference is a significant factor that influences the practice of induced abortion among women in South Korea. Also, based on the results of a longitudinal study of Matlab in Bangladesh, Bairagi (2001) reported that the effect of son preference on abortion and fertility behavior became stronger with declining fertility, because couples strive to have a certain number of sons and daughters within a smaller family size. Therefore, the use of prenatal strategies as measured by sex ratios at birth, and/or women's fertility behavior at low parities as measured by contraceptive use or parity progression, are often appropriate measures of gender preferences for children in lower fertility/transitioning societies. High sex ratios at birth reflecting son preference have been detected in China (e.g., Zeng et al. 1993), India (e.g., Arnold, Kishor, and Roy 2002), and South Korea (e.g., Park and Cho 1995). Son preference has also been observed in connection with the cessation of childbearing among women in countries such as Bangladesh (e.g., Rahman and DaVanzo 1993), Egypt (e.g., Vignoli 2006), India (e.g., Arokiasamy 2002), Nepal (e.g., Morgan and Niraula 1995), South Korea (e.g., Larsen, Chung, and Das Gupta 1998), and Vietnam (e.g., Bélanger et al. 2003).

On the other hand, in societies in which modern birth control methods and/or sexscreening technology have either not been adopted or have been limited, gender preferences may be better measured through the assessment of couples' postchildbearing behavior. In these societies, it is reasonable to assume that relatively little prenatal gender discrimination takes place, even when a gender preference exists. However, parents may engage in postnatal gender discrimination, especially against children of higher parity. This discrimination may take the form of explicit strategies, such as infanticide, neglect, or abandonment; but may also encompass more implicit behaviors, such as gender bias in the conscious or unconscious allocation of household resources, like food, education, and medical care. In this case, the appropriate indicators reflecting gender preferences for children are sex differences in the mortality, health, and the well-being of children. For example, Klasen (1996) discovered a small and rising anti-girl bias in sub-Saharan Africa, which was especially apparent in measures of mortality. Interestingly, there are a few accounts that associatee daughter preference 
with practices favoring girls in matrifocal societies in the Caribbean. A clear preference for daughters and childcare practices favoring female children have been observed among mothers in Jamaica (Sargent and Harris 1992). Daughter-biased parental practices have also been found in rural Dominica, where men are more likely to be poor and are less likely to attend secondary school than women (Quinlan 2006).

It should be noted that, in some societies, postnatal strategies may be used in addition to prenatal methods. In India, for example, discrimination against girls in healthcare and nutrition, though not universal, has been observed in families with a large number of siblings, and especially in families with older female siblings (Mishra, Roy, and Retherford 2004). Discriminatory practices against daughters have also been reported in China, where the vast majority of abandoned children are girls (Johnson, Huang, and Wang 1998), and where girls are less likely than boys to be enrolled in school (Wang 2005).

Evidently, the appropriate means of measuring gender preferences for children via behavior varies according to the societal context. Therefore, in order to investigate the magnitude and patterns of gender preferences across countries, I propose examining the underlying latent variable; namely, gender preference attitudes, which may be ascertained by surveying people about their gender preferences (e.g., their ideal gender composition of children). The assumption is that individuals have an ideal gender composition of children, and that this attitude is likely to translate into prenatal gender discrimination, differential fertility behavior based on the gender composition of surviving children, and/or postnatal discriminatory practices, depending on cultural norms.

Despite the suitability of attitudinal gender preference measures for cross-national examination, survey questions on women's ideal gender composition have been underutilized in cross-national studies. The Demographic and Health Surveys (DHS), which collects data on population and health measures from more than 75 lessdeveloped countries, have incorporated questions about gender preference attitudes in most surveys. Today, the DHS provides the largest and most recent data for crossnational comparisons of attitudinal measures of child gender preference. However, it appears that no scholars have explored these attitudinal variables from the DHS for comparative purposes since the publication of Arnold's 1997 report, which presents gender preference statistics from 17 DHS in 15 countries (Arnold 1997). Since this attitudinal variable of interest has been added to most recent DHS, data on a much greater number of countries from various regions of the world are now available. Thus, the DHS is an excellent source for up-to-date cross-national comparisons. 


\section{Data and methods}

In this study, I examine data from cross-sectional Demographic and Health Surveys (DHS) conducted in 50 less-developed countries in or after 2000. I analyze all of the DHS surveys that have been conducted since 2000 which include questions concerning women's ideals regarding the gender composition of children. If multiple surveys were conducted in a country during this time frame, I use the most recent survey. These criteria yielded 50 countries from four continents for examination.

The DHS collects data on a wide range of population and health topics, and provides comparable measures across more than 75 countries. The DHS has incorporated questions about child gender preferences since 1992, and is currently the only data source suitable for conducting a cross-national examination of attitudinal measures of child gender preference in less-developed countries. For most countries, data were collected from a sample of women of reproductive ages (15-49) at the time of the survey. A small percentage of 13- and 14-year-olds were also included in the samples of Bangladesh $(0.7 \%)$ and Colombia (8.8\%). Women were sampled regardless of their marital status except in a few countries, where only ever-married women were surveyed (these countries are Bangladesh, Indonesia, Jordan, Pakistan, Turkey, and Vietnam). In this study, I analyze never-married women and currently married women (including women who are currently in a stable union, such as living together). Nevermarried and currently married women are appropriate for my analysis, as I am interested in the gender preferences of women who are likely to be in their prime reproductive years, and whose gender preferences may translate into behaviors that favor one sex over the other. Widows and divorced women are excluded, as they may have already completed reproduction, and/or have low prospects of childbearing in the near future.

In the DHS, women with living children were asked, "If you could go back to the time you did not have any children and could choose exactly the number of children to have in your whole life, how many would that be?" Women without living children were asked, "If you could choose exactly the number of children to have in your whole life, how many would that be?" This initial query was followed by the question, "How many of these children would you like to be boys, how many would you like to be girls, and for how many would the sex not matter?" In every survey, the sum of the responses to these questions (i.e., the ideal number of boys, girls, and either sex) matched the response to the preceding question (i.e., the ideal total number of children).

Based on their responses to these questions, I classified the women into one of four gender preference categories: no gender preference (NP), balance preference (BP), son preference (SP), and daughter preference (DP). NP was assigned to women who provided a non-numeric answer (e.g., "It is up to God") as their ideal number of boys, 
girls, and children of either sex. NP was also assigned to women who stated that their ideal number of children of either sex is one or more, and to those who said their ideal number of both boys and girls is none. BP was assigned to women who said their ideal number of boys is equal to their ideal number of girls. Women who indicated that their ideal number of boys is greater than their ideal number of girls were placed in the SP category, and those who reported a preference for more girls than boys were placed in the DP category. A small percentage of women in each country indicated that their ideal is to have no children. Since these women were not asked to respond to the follow-up question on their ideal sex composition of children, they were not included in the analysis. A total of 664,554 women from 50 less-developed countries were assigned a gender preference.

I present percentage distributions of gender preferences for children by country. To account for the complex survey design employed by the DHS, descriptive statistics are obtained using appropriate survey weights and survey estimation procedures in Stata/SE 11.0.

\section{Results}

Tables 1 and 2 present information on the years the survey data were collected, the sample sizes for each country, and the percentage distributions of types of gender preferences by country. Of the 50 countries in the sample, 28 are located in various regions of sub-Saharan Africa. The remaining 22 countries are in Latin America and the Caribbean, Southern Asia, Southeastern Asia, Eastern Europe, Western Asia, and Northern Africa. 
Table 1: Sample size and descriptive statistics on type of gender preference by survey (non-sub-Saharan African countries)

\begin{tabular}{|c|c|c|c|c|c|c|}
\hline & \multicolumn{6}{|c|}{ Type of Gender Preference } \\
\hline & \multirow[b]{2}{*}{ Survey } & \multirow[b]{2}{*}{ Sample } & \multicolumn{2}{|c|}{$\% \quad \%$} & $\%$ & $\%$ \\
\hline & & & $\begin{array}{l}\text { No gender } \\
\text { preference }\end{array}$ & $\begin{array}{r}\text { Balance } \\
\text { preference }\end{array}$ & $\begin{array}{r}\text { Son } \\
\text { preference }\end{array}$ & $\begin{array}{l}\text { Daughter } \\
\text { preference }\end{array}$ \\
\hline Country & year & Size & $(\mathrm{NP})$ & (BP) & (SP) & (DP) \\
\hline Full Sample & $2000-2008$ & 664,554 & 21.6 & 47.9 & 17.7 & 12.8 \\
\hline \multicolumn{7}{|c|}{ Latin America \& the Caribbean } \\
\hline Bolivia & 2003 & 15,198 & 17.6 & 50.5 & 17.5 & 14.5 \\
\hline Colombia & 2005 & 34,046 & 15.3 & 50.9 & 12.8 & 20.9 \\
\hline Dominican Republic & 2007 & 21,681 & 11.9 & 41.2 & 13.7 & 33.2 \\
\hline Haiti & 2005 & 9,732 & 12.1 & 57.3 & 7.4 & 23.2 \\
\hline Honduras & 2005 & 16,770 & 26.9 & 36.9 & 16.9 & 19.3 \\
\hline Nicaragua & 2001 & 10,788 & 25.3 & 42.1 & 11.3 & 21.3 \\
\hline Peru & 2008 & 14,143 & 27.2 & 47.4 & 11.5 & 13.9 \\
\hline \multicolumn{7}{|l|}{ Southern Asia } \\
\hline Bangladesh $^{1}$ & 2007 & 10,132 & 23.9 & 60.3 & 13.8 & 1.9 \\
\hline India & 2005 & 117,186 & 22.4 & 52.9 & 22.1 & 2.5 \\
\hline Nepal & 2006 & 10,363 & 17.4 & 51.7 & 29.2 & 1.6 \\
\hline Pakistan $^{1}$ & 2006-2007 & 9,490 & 14.1 & 47.5 & 35.3 & 3.0 \\
\hline \multicolumn{7}{|l|}{ South-Eastern Asia } \\
\hline Cambodia & 2005 & 15,309 & 5.3 & 53.4 & 14.5 & 26.8 \\
\hline Indonesia $^{1}$ & 2007 & 30,837 & 26.5 & 53.3 & 9.5 & 10.7 \\
\hline Philippines & 2008 & 12,828 & 8.9 & 55.7 & 14.5 & 20.9 \\
\hline Vietnam $^{1}$ & 2002 & 5,340 & 21.5 & 64.1 & 10.9 & 3.4 \\
\hline \multicolumn{7}{|l|}{ Eastern Europe } \\
\hline Ukraine & 2007 & 5,660 & 20.3 & 52.7 & 10.2 & 16.8 \\
\hline \multicolumn{7}{|l|}{ Western Asia } \\
\hline Armenia & 2005 & 6,057 & 6.6 & 60.6 & 19.9 & 12.9 \\
\hline Azerbaijan & 2006 & 7,771 & 9.9 & 63.7 & 18.2 & 8.2 \\
\hline Jordan $^{1}$ & 2007 & 10,210 & 27.2 & 50.8 & 18.2 & 3.8 \\
\hline Turkey $^{1}$ & 2003 & 7,669 & 64.0 & 26.7 & 5.1 & 4.2 \\
\hline \multicolumn{7}{|l|}{ Northern Africa } \\
\hline Egypt $^{1}$ & 2008 & 15,386 & 41.4 & 41.0 & 12.6 & 5.0 \\
\hline Morocco & 2003 & 15,849 & 27.3 & 57.1 & 8.2 & 7.3 \\
\hline
\end{tabular}

${ }^{1}$ Only ever married women were surveyed in these countries 
Fuse: Variations in attitudinal gender preferences for children across 50 less-developed countries

Table 2: $\quad$ Sample size and descriptive statistics on type of gender preference by survey (sub-Saharan African countries)

\begin{tabular}{|c|c|c|c|c|c|c|}
\hline & \multicolumn{6}{|c|}{ Type of Gender Preference } \\
\hline & \multirow[b]{2}{*}{ Survey } & \multirow[b]{2}{*}{ Sample } & $\%$ & $\%$ & $\%$ & $\%$ \\
\hline & & & $\begin{array}{l}\text { No gender } \\
\text { preference }\end{array}$ & $\begin{array}{r}\text { Balance } \\
\text { preference }\end{array}$ & $\begin{array}{r}\text { Son } \\
\text { preference }\end{array}$ & $\begin{array}{l}\text { Daughter } \\
\text { preference }\end{array}$ \\
\hline Country & year & Size & $(\mathrm{NP})$ & (BP) & $(\mathrm{SP})$ & (DP) \\
\hline \multicolumn{7}{|l|}{ Eastern Africa } \\
\hline Ethiopia & 2005 & 11,381 & 14.5 & 55.9 & 22.1 & 7.6 \\
\hline Kenya & 2003 & 7,255 & 28.7 & 43.7 & 15.1 & 12.5 \\
\hline Madagascar & 2003 & 6,836 & 15.9 & 56.7 & 16.3 & 11.2 \\
\hline Malawi & 2004 & 10,156 & 11.1 & 54.7 & 13.1 & 21.2 \\
\hline Mozambique & 2003 & 10,585 & 8.0 & 53.0 & 18.4 & 20.6 \\
\hline Rwanda & 2005 & 9,698 & 17.9 & 51.4 & 18.3 & 12.4 \\
\hline Tanzania & 2004 & 9,285 & 15.4 & 49.2 & 19.0 & 16.4 \\
\hline Uganda & 2006 & 7,384 & 17.5 & 56.1 & 10.3 & 16.1 \\
\hline Zambia & 2007 & 6,197 & 21.6 & 43.7 & 14.0 & 20.8 \\
\hline Zimbabwe & $2005-2006$ & 7,474 & 9.6 & 53.9 & 17.4 & 19.1 \\
\hline \multicolumn{7}{|l|}{ Middle Africa } \\
\hline Cameroon & 2004 & 9,681 & 37.0 & 29.9 & 15.6 & 17.5 \\
\hline Chad & 2004 & 5,457 & 28.1 & 36.0 & 23.6 & 12.3 \\
\hline Congo Brazzaville & 2005 & 6,051 & 27.1 & 33.5 & 18.0 & 21.5 \\
\hline Congo Democratic Republic & 2007 & 8,911 & 18.4 & 35.0 & 26.9 & 19.8 \\
\hline Gabon & 2000 & 5,382 & 16.1 & 51.4 & 12.6 & 19.9 \\
\hline \multicolumn{7}{|l|}{ Southern Africa } \\
\hline Lesotho & 2004 & 5,875 & 6.1 & 56.8 & 18.7 & 18.4 \\
\hline Namibia & 2006-2007 & 8,483 & 8.7 & 52.2 & 15.1 & 24.0 \\
\hline Swaziland & $2006-2007$ & 4,239 & 4.0 & 59.9 & 21.8 & 14.4 \\
\hline \multicolumn{7}{|l|}{ Western Africa } \\
\hline Benin & 2006 & 16,872 & 26.4 & 48.7 & 15.1 & 9.8 \\
\hline Burkina Faso & 2003 & 11,968 & 23.1 & 33.1 & 33.3 & 10.6 \\
\hline Ghana & 2008 & 4,477 & 12.7 & 46.7 & 19.4 & 21.3 \\
\hline Guinea & 2005 & 7,548 & 21.2 & 40.9 & 26.5 & 11.4 \\
\hline Liberia & 2007 & 6,225 & 7.6 & 51.8 & 18.5 & 22.2 \\
\hline Mali & 2006 & 14,015 & 23.3 & 38.0 & 29.3 & 9.5 \\
\hline Niger & 2006 & 8,703 & 35.5 & 25.5 & 27.8 & 11.2 \\
\hline Nigeria & 2008 & 31,358 & 26.0 & 39.9 & 24.4 & 9.7 \\
\hline Senegal & 2005 & 13,798 & 25.9 & 30.0 & 36.5 & 7.6 \\
\hline Sierra Leone & 2008 & 6,815 & 8.0 & 58.9 & 16.1 & 17.0 \\
\hline
\end{tabular}


Figures 1 and 2 provide visual presentations of the magnitude and patterns of gender preferences cross-nationally. Looking at Figure 1, we can see that balance is the most popular type of gender preference in all non-sub-Sahara African countries, except in Turkey and Egypt, where no specific gender is the most common of all the preferences. In half of these countries, the second most common preference is no gender preference. When we focus on the preferences for a specific gender (i.e., either a son preference or a daughter preference), we can observe a variation across regions and countries. When we compare the percentage of women who have son and daughter preferences, we find that, in all of the Latin American/Caribbean countries except for Bolivia, more women report having a daughter preference. The percentage of women exhibiting a daughter preference is especially high in the Dominican Republic (33.2\%) and in Haiti (23.2). This is consistent with prior anthropological research in the Caribbean, which found that matrifocal kinship patterns are prevalent, and that daughters are thus highly valued (Quinlan 2006). Daughter preference is more common than son preference in Cambodia and the Philippines, where $26.8 \%$ and $20.9 \%$ of women have a daughter preference, compared to $14.5 \%$ and $14.5 \%$ with a son preference, respectively. In addition, the percentage of Indonesian women with a daughter preference $(10.7 \%)$ is slightly higher than those with a son preference $(9.5 \%)$. This is in line with the results of a study by Arnold and Kuo's (1984), which found a tendency towards daughter preference in a few Southeast Asian countries with a Malayo-Polynesian background, including Indonesia and the Philippines. Consistent with prior studies, son preference is more common than daughter preference in the countries of Southern Asia, Western Asia, and Northern Africa. The percentage of women with a son preference is highest in Pakistan, at 35.3\%; followed by Nepal, at 29.2\%. Southern Asian countries also have extremely low percentages of women exhibiting a daughter preference. In Bangladesh, India, Nepal, and Pakistan, only 1.9\%, $2.5 \%, 1.6 \%$, and $3.0 \%$ of women reported a daughter preference, respectively. 
Fuse: Variations in attitudinal gender preferences for children across 50 less-developed countries

\section{Figure 1: Percentage in each gender preference category by country (non-sub-Saharan African countries)}

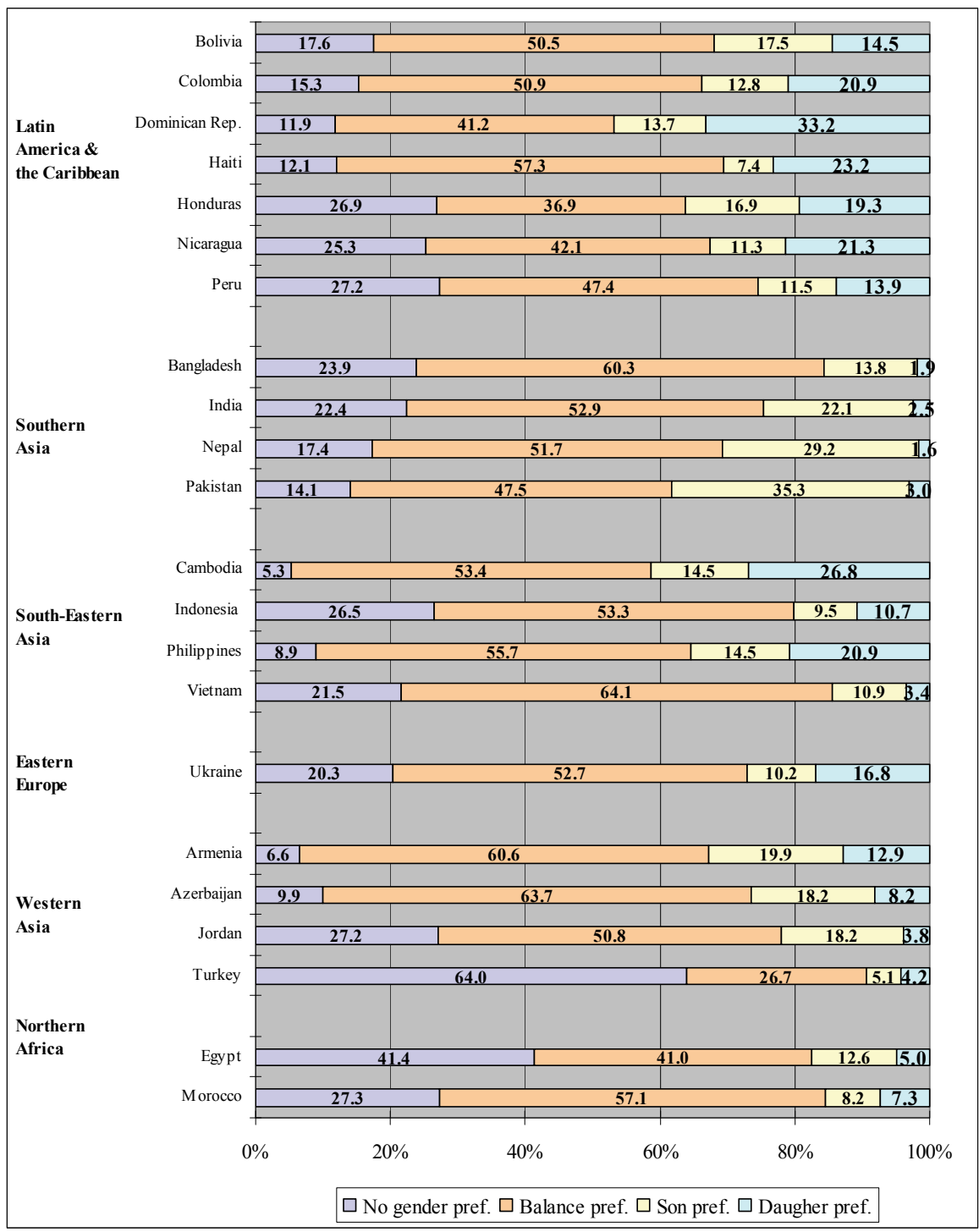


Figure 2: Percentage in each gender preference category by country (sub-Saharan African countries)

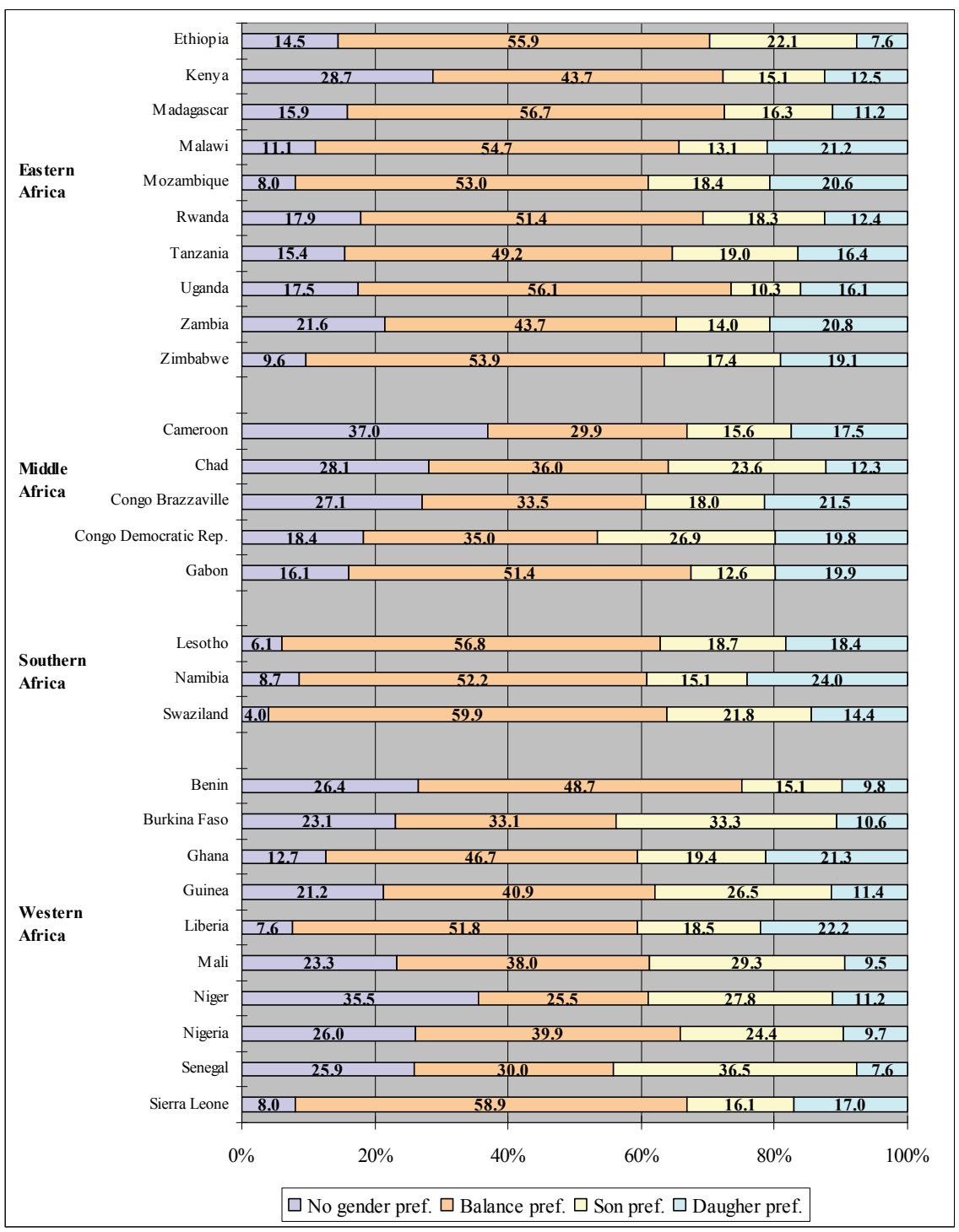


Turning to gender preference distributions in sub-Saharan Africa (Figure 2), we find that balance is the most common type of preference. Of the 28 sub-Saharan African countries, balance is the most popular preference in 24 countries. No gender preference is the most common type of preference in two of the 28 countries. Comparing the percentage of women with a son preference to those with a daughter preference, we find that some variation can be observed. In 16 of the 28 sub-Sahara African countries, more women have a son preference than a daughter preference. While son preference is observed in every sub-region within sub-Saharan Africa, it appears to be particularly prevalent in Western Africa. Western African countries that were, based on earlier DHS data, found to have substantial levels of son preference in the early 1990s (Arnold 1997) continued to exhibit considerable biases towards sons in the 2000s (i.e., Mali and Senegal). Today, son preference is especially prominent in Burkina Faso and Senegal, where more than $30 \%$ of women have a son preference. Interestingly, daughter preference is more prevalent than son preference in 12 of the 28 countries, and these countries are dispersed across all the regions of sub-Saharan Africa.

\section{Conclusions}

A large number of country-specific studies have examined gender preferences for children by analyzing various behavioral measures, such as skewed sex ratios, sex imbalance in infant mortality, and sibling size and order. This study examined crossnational variations in women's gender preferences for children by taking advantage of 50 recent Demographic and Health Surveys that included attitudinal questions about women's gender preferences for children. To my knowledge, there are no recent comparative studies that have systematically examined gender preference attitudes, despite the suitability of this variable for the purposes of cross-national comparison.

This research has found wide variations in the distribution of the types of gender preference across countries and regions. In the vast majority of countries, the most common type of gender preference is balance; that is, a preference for an equal number of sons and daughters. When we compare the prevalence of son preference relative to daughter preference, a large degree of variation becomes evident. Daughter preference predominates in Latin America and the Caribbean (with the exception of Bolivia), as well as in several Southeast Asian countries. Son preference is prevalent in Southern Asia, Western Asia, and Northern Africa. In sub-Saharan Africa, son preference prevails in 16 of the 28 countries examined; while daughter preference is most commonly observed in the remaining countries. Thus, this cross-national comparison has demonstrated that son preference is not always the dominant type of gender preference, and that daughter preference is common in many societies. This is an 
intriguing finding, given that most previous studies of gender preference in developing countries have focused heavily on son preference. The discovery that different societies have different attitudes about gender preference suggests that more research is needed to help us better understand the context of each specific situation.

\section{Limitations}

This study has limitations. First, the gender preferences of men were not analyzed in this study. In developing countries, men tend to have a stronger preference for sons than women (see Mason and Taj 1987 for a review). Also, it has been reported that gender preferences often differ for men and women, with women preferring daughters and men preferring sons for companionship (Williamson 1976). Therefore, examining women's gender preferences for children may provide only one side of the story. Nonetheless, an overwhelming percentage of women still expressed a desire to have one or more sons (i.e., they indicated a balance preference or a son preference) in the majority of the countries examined. Moreover, in over half of the countries studied, the percentage of women who wanted more sons than daughters exceeded that of women who expressed a desire to have more daughters than sons. This may suggest that these women want sons for vital reasons, such as economic security and maintaining their status within the traditional family structure.

Second, while questions on the ideal gender composition of children are not threatening or sensitive in nature, they may produce some level of social desirability bias. Respondents may provide more or less socially acceptable responses, especially in societies that value gender equity, or in societies with social norms on the desirable sex composition of children. The extent to which stated gender preferences reflect social desirability is unknown and is beyond the scope of this study, but this issue is worth investigating in future research.

Third, distributions of gender preference attitudes are for comparative and illustrative purposes. I reiterate that the extent to which those attitudes translate into actual reproductive behavior vary across societies. Therefore, the possible implications of the magnitude of gender preference attitudes need to be considered contextspecifically.

Finally, this paper merely presents descriptive findings, and does not focus on the relationships between country-level factors and certain types of gender preference. However, since there is enough DHS data, conducting a country-level analysis may be worthwhile in future research. For example, further research may explore what societal characteristics (e.g., level of development, media prevalence, religion, women's 
position inside and outside the family) shape individuals' gender preferences for children.

\section{Policy implications}

Gender preferences for children in less-developed countries have been of concern to many scholars and policy makers because of potential negative social and demographic consequences of these preferences. This study found an obvious tendency towards a balance preference and/or a preference for one gender over the other in most countries. Since these attitudes may, depending on the societal context, translate into various behaviors that are unfavorable for the health and well-being of children of the lessdesired gender, they need to be closely monitored. My findings may also provide a starting point for donors and policy makers in identifying the countries where undesirable outcomes are likely, and in considering what approaches they might use to address or prevent these outcomes.

Sons and daughters are wanted for different reasons in transitioning countries (Arnold and Kuo 1984). Thus, gender preferences for children are shaped by the relative importance of the expected qualities of sons and daughters. This perception of relative importance is determined by the societal context in which people live. Hence, in areas where a strong gender preference is evident, efforts to change perceptions of gender norms may be imperative to improve the survival and well-being of children of the less-desired gender. In patriarchal societies, sons may be desired for the continuity of the family line and for future economic returns. Efforts to address patriarchal gender norms and to expand educational and occupational opportunities for females may be necessary if girls are to be perceived as important and desired.

While there are many studies that have described the unfavorable implications of son preference, the implications of daughter preference are not as widely known. This study found a tendency towards daughter preference in parts of Latin America and the Caribbean, Southeast Asia, sub-Saharan Africa, and the Ukraine. As cited earlier, girlfavoring practices reflecting daughter preference have been observed in the Caribbean. Thus, it is also advisable to monitor for possible social and demographic implications in countries where a preference for daughters predominates.

\section{Acknowledgments}

I wish to thank Macro International Inc. (currently ICF Macro) and USAID for providing me with financial support in completing an earlier version of this paper. I am 
grateful to Vinod Mishra, Simona Bignami, Sarah Bradley, Yuan Cheng, Shane Khan, and Rand Stoneburner for their helpful advice and assistance with data. I also acknowledge fellow participants of the DHS Fellows' Workshop for providing me with insightful comments. Finally, I wish to thank Edward Crenshaw, John Casterline, and Elizabeth Cooksey for their valuable advice on the project. 


\section{References}

Arnold, F. (1997). Gender Preferences for Children. Demographic and Health Surveys Comparative Studies No. 23.

Arnold, F. and Kuo, E.C.Y. (1984). The value of daughters and sons: A comparative study of the gender preferences of parents. Journal of Comparative Family Studies 15: 299-318.

Arnold, F., Kishor S., and Roy, T.K. (2002). Sex-selective abortions in India. Population and Development Review 28: 759-785.

Arokiasamy, P. (2002). Gender preference, contraceptive use and fertility in India: Regional and development influences. International Journal of Population Geography 8: 49-67. doi:10.1002/ijpg.236.

Bairagi, R. (2001). Effects of sex preference on contraceptive use, abortion and fertility in Matlab, Bangladesh. International Family Planning Perspectives 27: 137-143. doi:10.2307/2673835.

Bélanger, D., Thi Hai Oanh, K., Jianye, L., Thanh Thuy, L., and Viet Thanh, P. (2003). Are sex ratios at birth increasing in Vietnam? Population (English Edition) 58: 231-250. doi:10.3917/pope.302.0231.

Chung, W. and Das Gupta, M. (2007). The decline of son preference in South Korea: The role of development and social policy. Population and Development Review 33: 757-783. doi:10.1111/j.1728-4457.2007.00196.x.

Goodkind, D. (1996). On substituting sex preference strategies in East Aisa: Does prenatal sex selection reduce postnatal discrimination? Population and Development Review 22: 111-125. doi:10.2307/2137689.

Guilmoto, C.Z. (2010). Longer-term disruptions to demographic structures in China and India resulting from skewed sex ratios at birth. Asian Population Studies 6: 3-24. doi:10.1080/17441731003603371.

Johnson, K., Huang, B., and Wang, L. (1998). Infant abandonment and adoption in China. Population and Development Review 24: 469-510. doi:10.2307/2808152.

Klasen, S. (1996). Nutrition, health and mortality in Sub-Saharan Africa: Is there a gender bias? Journal of Development Studies 32: 913-943.

Larsen, U., Chung, W., and Das Gupta, M. (1998). Fertility and son preference in Korea. Population Studies 52: 317-325. 
Mason, K.O. and Taj, A.M. (1987). Differences between women's and men's reproductive goals in developing countries. Population and Development Review 13: 611-638. doi:10.2307/1973025

Mishra, V., Roy, T.K., and Retherford, R.D. (2004). Sex differentials in childhood feeding, health care, and nutritional status in India. Population and Development Review 30: 269-295. doi:10.1111/j.1728-4457.2004.013_1.x.

Morgan, S.P. and Niraula, B.B. (1995). Gender inequality and fertility in two Nepali villages. Population and Development Review 21: 541-561. doi:10.2307/2137749.

Park, C.B. and Cho, N.-H. (1995). Consequences of son preference in a low-fertility society: Imbalance of the sex ratio at birth in Korea. Population and Development Review 21: 59-84. doi:10.2307/2137413.

Quinlan, R.J. (2006). Gender and risk in a matrifocal Caribbean community: A view from behavioral ecology. American Anthropologist 108: 464-479. doi:10.1525/aa.2006.108.3.464.

Rahman, M. and DaVanzo, J. (1993). Gender preference and birth spacing in Matlab, Bangladesh. Demography 30: 315-332. doi:10.2307/2061643.

Sargent, C. and Harris, M. (1992). Gender ideology, childrearing, and child health in Jamaica. American Ethnologist 19: 523-537. doi:10.1525/ae.1992.19.3.02a00060.

United Nations (2000). The world's women 2000: Trends and statistics. New York: United Nations.

Vignoli, D. (2006). Fertility change in Egypt: From second to third birth. Demographic Research 15(18): 499-516. doi:10.4054/DemRes.2006.15.18.

Waldron, I. (1983). Differences in human mortality: The role of genetic factors. Social Science and Medicine 17: 321-333.

Waldron, I. (1998). Sex differences in infant and early childhood mortality: Major causes of death ad possible biological causes." In: United Nations (ed.). Too young to die: Genes or gender. New York, NY: United Nations: 64-83.

Wang, W. (2005). Son preference and educational opportunities of children in China"I wish you were a boy!" Gender Issues 22: 3-30. doi:10.1007/s12147-0050012-4. 
Fuse: Variations in attitudinal gender preferences for children across 50 less-developed countries

Williamson, N.E. (1976). Sons or daughters: A cross-cultural survey of parental preferences. Beverly Hills, CA: Sage Publications, Inc.

Zeng, Y., Tu, P., Gu, B., Xu, Y., Li, B., and Li, Y. (1993). Causes and implications of the recent increase in the reported sex ratio at birth in China. Population and Development Review 19: 283-302. 